\title{
OS LAGARTOS GIMNOFTALMÍDEOS (SQUAMATA: GYMNOPHTHALMIDAE) DO CARIRI PARAIBANO E DO SERIDÓ DO RIO GRANDE DO NORTE, NORDESTE DO BRASIL: CONSIDERAÇÕES ACERCA DA DISTRIBUIÇÃO GEOGRÁFICA E ECOLOGIA
}

\author{
Fagner Ribeiro Delfim ${ }^{1 *}$ \& Eliza Maria Xavier Freire ${ }^{2,3}$ \\ ${ }^{1}$ Programa de Pós-Graduação em Ciências Biológicas - Área de Concentração em Zoologia. Departamento de Sistemática e Ecologia, Centro de Ciências \\ Exatas e da Natureza, Universidade Federal da Paraíba. CEP: 58051-900. João Pessoa, PB, Brasil. \\ ${ }^{2}$ Departamento de Botânica, Ecologia e Zoologia, Universidade Federal do Rio Grande do Norte. CEP: 59072-970. Natal, RN, Brasil \\ ${ }^{3}$ Professora credenciada no PPG em Ciências Biológicas - Área de Concentração em Zoologia, Universidade Federal da Paraíba. \\ *E-mail: fdruida@yahoo.com.br
}

\section{RESUMO}

O presente estudo objetivou inventariar a fauna de gimnoftalmídeos em algumas áreas de Caatinga no Cariri Paraibano e no Seridó do Rio Grande do Norte, mapear suas respectivas distribuições geográficas e discorrer sobre a história natural e uso do hábitat das mesmas. Quatro espécies de lagartos da família Gymnophthalmidae (Anotosaura vanzolinia; Acratosaura mentalis; Micrablepharus maximiliani e Vanzosaura rubricauda) foram registradas nas áreas amostradas. Apenas Vanzosaura rubricauda foi encontrada em todas as áreas exploradas, enquadrando-se em sua condição de táxon amplamente distribuído nas formações de vegetação aberta da América do Sul. Anotosaura vanzolinia e Acratosaura mentalis foram registradas em novas localidades, ampliando desta maneira suas respectivas distribuições no estado da Paraíba. A proposta de distribuição das espécies de gimnoftalmídeos ocorrentes na Caatinga foi mantida, sendo, portanto, improvável a ocorrência das espécies ligadas ao Campo de Dunas Paleoquaternárias do Médio Rio São Francisco em localidades de caatingas típicas, sem solos arenosos e/ou que não tiveram ligação histórico-geológica com esta área. No entanto, não se pode descartar a possibilidade de novos registros de lagartos da família Gymnophthalmidae para a Caatinga.

Palavras-chave: Distribuição geográfica, espécies endêmicas, relictual, Rio São Francisco, dunas paleoquaternárias.

\begin{abstract}
THE GYMNOPHTALMID LIZARDS (SQUAMATA: GYMNOPHTHALMIDAE) OF THE CARIRI REGION OF PARAÍBA AND SERIDÓ OF RIO GRANDE DO NORTE, NORTHEASTERN BRAZIL: CONSIDERATIONS ABOUT GEOGRAPHIC DISTRIBUTION AND ECOLOGY. The present study aimed to inventory the fauna of gimnophthalmid lizards in some areas of Caatinga in the Cariri region of Paraíba and Seridó of Rio Grande do Norte, map their respective geographical distribution, discourse on their natural history and use of habitat. Four species of gymnophthalmid lizards (Anotosaura vanzolinia; Acratosaura mentalis; Micrablepharus maximiliani and Vanzosaura rubricauda) were recorded in the sampled areas. Only Vanzosaura rubricauda was found in all explored areas, accordingly to its classification as a taxon widely distributed in the open vegetation formations of South America. Anotosaura vanzolinia and Acratosaura mentalis were recorded in new localities, extending their respective distributions in the State of Paraíba. The present hypothesis of distribution of the gymnophthalmid species that occur in the Caatinga biome was maintained. Therefore, we find it improbable that species that occur in the Paleoquaternary SandDunes of the Middle São Francisco River may also occur in typical caatinga localities without sandy soils and/ or not connected historically-geologically to that. However, the possibility of new records of gymnophthalmid lizards for the Caatinga biome can not be discard.
\end{abstract}

Keywords: Geographic distribution, endemic species, relictual, São Francisco River, Paleoquaternary sand dunes. 


\section{INTRODUÇÃO}

Os Gymnophthalmidae são lagartos de pequeno tamanho corporal (cerca de 4 a $15 \mathrm{~cm}$ de comprimento rostro-cloacal) que se distribuem do Sul do México à Argentina, no Caribe e em algumas ilhas continentais da América Central e do Sul, onde vivem relacionados ao folhedo de florestas tropicais e subtropicais ou ocultos na serrapilheira e na vegetação rasteira das áreas abertas (Vanzolini et al. 1980, Rodrigues 1995, Rodrigues et al. 2001).

Desde o reconhecimento dos Gymnophthalmidae como distinto dos Teiidae, a sistemática do primeiro táxon tem sido marcada pela descoberta de numerosos gêneros e espécies (Cunha et al. 1991, Rodrigues 1991a, 1991b, 1991c, 1996a, 1996b, 1997, Vanzolini \& Carvalho 1991, Hoogmoed \& Ávila-Pires 1992, Carvalho 1997, Ávila-Pires \& Vitt 1998, MacCulloch \& Lathrop 2001, Pellegrino et al. 2001, Rodrigues et al. 2001, 2002a, 2002b, 2005), bem como por estudos citogenéticos e moleculares das espécies constituintes (Cole et al. 1993, Yonenaga-Yassuda et al. 1995, Pellegrino et al. 1999a, 1999b, 2001, Yonenaga-Yassuda \& Rodrigues 1999, Bertolloto et al. 2002, Castoe et al. 2004), os quais culminaram com novas proposições de classificação para esta família (Pellegrino et al. 2001, Castoe et al. 2004).

A maioria das espécies recentemente descritas foi descoberta em localidades de Caatinga, em especial nas dunas paleoquaternárias do médio Rio São Francisco (Rodrigues, 1991a, 1991b, 1991c), de onde sete destas são consideradas endêmicas (Rodrigues 1996b).

Se por um lado, a descrição de novos táxons possibilitou o conhecimento da riqueza de espécies e a elucidação de suas relações filogenéticas, por outro, permanecem extensas lacunas geográficas a serem investigadas visando o conhecimento sobre a distribuição real dos gimnoftalmídeos e/ou seus respectivos padrões de distribuição.

Vanzolini et al. (1980) fizeram comentários acerca da biologia das espécies de répteis que ocorrem na Caatinga, embora posteriormente, várias espécies tenham sido descritas para esta região, principalmente de gimnoftalmídeos. Rodrigues (2003) reconhece que a fauna de répteis da Caatinga é relativamente bem conhecida no que diz respeito às espécies mais comuns, mas ressalta que este conhecimento é insatisfa- tório, pois faltam boas amostragens de formas subterrâneas, fossoriais e/ou raras, e ainda existem imensas lacunas geográficas a serem averiguadas dentro do bioma (das 150 localidades distribuídas pelos estados do Piauí, Ceará, Rio Grande do Norte, Paraíba, Pernambuco, Alagoas, Sergipe e Bahia, representadas na coleção herpetológica do Museu de Zoologia da Universidade de São Paulo - MZUSP, apenas 24 podem ser consideradas bem amostradas e, mesmo assim, a maioria só em relação às espécies mais comuns e simples de serem coletadas).

De acordo com Rodrigues (2003), a hipótese de que a fauna de lagartos da Caatinga é constituída unicamente por espécies típicas do grande cinturão diagonal de formações vegetais abertas que se estende do Chaco até o nordeste brasileiro (Vanzolini 1974, 1976, Rodrigues 1986a, 1986b) não passa de uma precipitação, baseada em coleções mal representadas, amostragens insuficientes, na falta de uma melhor cobertura dos ecossistemas adjacentes, e num conceito de Caatinga que não encerra informações históricas necessárias para se compreender a evolução de sua fauna. A exemplo, Vanzolini \& Ramos (1977), analisando um grupo de microteíideos relacionados, concordaram que a maioria das informações era insuficiente para interpretação de suas distribuições, entretanto consideraram as espécies como stranded (encalhadas), restritas a situações marginais em áreas heterogêneas, devido à falta de condições atuais propícias a suas expansões. Especialmente na Caatinga, algumas questões relacionadas aos padrões de distribuição das espécies desta família são intrigantes: os únicos gimnoftalmídeos encontrados em Exu, estado de Pernambuco, são Micrablepharus maximiliani e Vanzosaura rubricauda (Vanzolini 1974, Vanzolini et al. 1980, Rodrigues 1996b); em Cabaceiras, Paraíba, além daquela última, ocorrem Acratosaura mentalis e Anotosaura vanzolinia (Rodrigues 1986b, 1996b).

Rodrigues (1995), na mais recente tentativa de associar a filogenia e a história geográfica de uma radiação de gimnoftalmídeos, concluiu que a exceção dos gêneros Micrablepharus e Vanzosaura (além dos gêneros Tretioscincus e Gymnophthalmus - de distribuição amazônica), ambos amplamente distribuídos na maior parte da diagonal de formações vegetais abertas da América do Sul, todos os demais gêneros componentes da tribo 
Gymnophthalmini (microteíideos sem pálpebras) tinham sua história associada ao campo de dunas paleoquaternárias do Rio São Francisco: as duas espécies de Procellosaurinus, Psilophthalmus paeminosus, Notobachia ablephara e as três espécies de Calyptommatus, todas consideradas estritamente endêmicas daquelas dunas e apresentam uma rígida fidelidade ecológica aos solos arenosos (Rodrigues 1991a, 1991b, 1991c, 1996b).

Atualmente, alguns destes endemismos estão descaracterizados, uma vez que Psilophthalmus paeminosus foi encontrado na Estação Ecológica de Xingó, estado de Alagoas, região do baixo Rio São Francisco (Delfim et al. 2006) e uma nova espécie de Calyptommatus, gênero considerado endêmico daquelas dunas por Rodrigues (1991a), foi descrita da Serra das Confusões, estado do Piauí (Rodrigues et al.2001). No entanto, a ligação geográfica passada entre estas duas áreas e o campo de dunas do Rio São Francisco parecem ser claras.

Rodrigues (2003) relaciona 15 espécies de gimnoftalmídeos para a Caatinga, sendo 13 destas consideradas como tendo distribuição relictual.Destas, oito são espécies estritamente relacionadas ao campo de dunas do médio Rio São Francisco. Apenas duas espécies são tratadas como amplamente distribuídas (Micrablepharus maximiliani e Vanzosaura rubricauda). Borges-Nojosa \& Cascon (2005) registraram recentemente mais uma espécie para o bioma Caatinga, Colobosaura modesta, aumentando o número para 16 espécies; esta é considerada como tendo distribuição relictual.

Os fatos acima relatados demonstram claramente que a fauna de gimnoftalmídeos das Caatingas ainda é insuficientemente conhecida e que não se conhece a distribuição geográfica real de grande parte das espécies, dados imprescindíveis para o conhecimento sobre a história geográfica do grupo. Deste modo, o presente estudo visa inventariar a fauna de lagartos da Família Gymnophthalmidae de áreas pouco investigadas do Bioma Caatinga, especialmente das regiões do Seridó no Rio Grande do Norte e do Cariri Paraibano, discorrer sobre aspectos da história natural e utilização de hábitat das espécies, além de comparar a lista de espécies obtidas com aquelas pré-existentes para outras localidades na Caatinga, mapeando assim suas respectivas distribuições geográficas.

\section{ÁREAS DE ESTUDO}

\section{CARIRI PARAIBANO}

O Cariri Paraibano, também conhecido como Cariris Velhos, situa-se na mesorregião da Borborema, na porção centro-sul do estado da Paraíba, e constitui uma das áreas mais secas do país (Ab'Saber 1969). A grande área dos Cariris pode ser classificada como uma faixa subdesértica quente de tendência tropical, com predomínio do clima do tipo semi-árido, apresentando temperatura média anual em torno de $25^{\circ} \mathrm{C}$, umidade relativa do ar em torno de $65 \%$ e índice pluviométrico de cerca de $300 \mathrm{~mm}$ anuais, com distribuição muito irregular (Ab'Saber 1974). A estação seca é muito longa, com duração superior a oito meses. No Cariri observam-se diferentes tipos de vegetação do Domínio das Caatingas (Ab'Saber 1967, 1969) e elevações que variam entre 400 e $600 \mathrm{~m}$ de altitude.

\section{São João do Cariri}

O município de São João do Cariri localiza-se na microrregião do Cariri Oriental, parte integrante do Cariri Paraibano, e possui uma área de $702 \mathrm{~km}^{2}$. A estação chuvosa local não é bem definida, podendo a estação seca, em alguns anos praticamente sem chuva, durar até 10 meses consecutivos. A média anual de precipitações é de $387 \mathrm{~mm}$ com 30 dias de chuva em média (Núcleo de Metereologia Aplicada 1987) e a média de temperatura anual varia entre 28,5 e $30^{\circ} \mathrm{C}$ (Governo do Estado da Paraíba/SE/ UFPB 1985).

Dois pontos de coleta foram selecionados neste município: a Estação Experimental de São João do Cariri -EESJC $\left(07^{\circ} 25^{\prime} \mathrm{S}, 36^{\circ} 30^{\prime} \mathrm{W}\right)$ somada a um sítio adjacente a mesma, Sítio Olho D’água, e o sítio de Zé Galego -SZG- (7²8’'S; 36³1’W).

A área da EESJC possui aproximadamente $381 \mathrm{ha}$. O solo é raso e pedregoso, com capacidade de infiltração e retenção hídrica moderada. A vegetação típica do local é a caatinga arbustiva esparsa, embora esta se encontre muito modificada devido à exploração seletiva de madeira para diversos fins que ocorreu durante o século XX. Atualmente esta área é utilizada para a criação de caprinos e ovinos de forma experimental, que acabam consumindo a maior parte 
da vegetação herbácea da área (Mélo \& Bandeira 2004). O Sítio Olho D'água situa-se ao lado da EESJC, portanto suas características são semelhantes às descritas acima.

O SZG possui vegetação semelhante a das áreas anteriores, apesar de aparentar um menor impacto, sendo esta mais densa e apresentando árvores altas esparsas. Um grande rio intermitente (que formou poças d'água durante a estação chuvosa no período de coletas) corta a área, sendo o responsável pela existência de solos arenosos que acompanham seu leito e se prolongam por aproximadamente $50 \mathrm{~m}$ de distância de sua margem.

\section{Reserva Particular do Patrimônio Natural Fazenda Almas}

A RPPN Fazenda Almas - RFA (07 $28^{\circ} \mathrm{S}$; $36^{\circ} 52^{\prime} \mathrm{W}$ ) localiza-se entre os municípios de São José dos Cordeiros e Sumé, na microrregião do Cariri Ocidental, e possui uma área de aproximadamente 3505 ha. Apresenta média anual de precipitação de 560 $\pm 230 \mathrm{~mm}$, que se concentra nos meses de fevereiro a abril (Núcleo de Metereologia Aplicada 1987). A vegetação varia de uma caatinga arbórea densa a uma caatinga arbórea mais aberta (Barbosa et al. 2003), entremeada por lajedos com flora característica. A ocorrência de amplos serrotes pedregosos na área colabora com a manutenção da umidade em pequenos hábitats formados principalmente em seus sopés. Nestes locais as árvores parecem permanecer verdes durante um período maior do ano (com exceção dos anos mais secos, segundo os habitantes locais), o que torna possível a formação de micro-ambientes diferenciados do restante da área, com muito folhiço acumulado e sombreamento. $\mathrm{O}$ acúmulo de matéria orgânica e sua decomposição auxiliam na formação de um solo com muito húmus.

A temperatura anual média e a umidade relativa do ar são de $25^{\circ} \mathrm{C} \mathrm{e} 65 \%$, respectivamente. Aárea da RPPN Fazenda Almas é bem conservada, representando uma das poucas localidades, ou talvez a única, encontrada nesta condição no Cariri Paraibano.

\section{SERIDÓ POTIGUAR}

A microrregião do Seridó potiguar localiza-se ao sul da mesorregião central do estado do Rio Grande do Norte (9554Km² de extensão), formando com o Cariri paraibano um continuum representativo do Domínio Morfoclimático das Caatingas nordestinas (Ab'Saber 1974). Caracteriza-se por climas semiáridos quentes (média térmica anual entre 26 $27^{\circ} \mathrm{C}$ ), umidade relativa variando entre $50 \%$ a $80 \%$ e precipitações escassas muito irregulares (500 a $800 \mathrm{~mm}$ em média), com os meses de março a maio sendo os mais chuvosos. Possui tipos variados de vegetação xeromórfica (Ab'Saber 1974), com uma grande parcela ocupada por uma vegetação arbóreoarbustiva (Varela-Freire 2002).

\section{Estação Ecológica do Seridó}

A Estação Ecológica do Seridó - $\operatorname{ESEC~}\left(06^{\circ}\right.$ $34^{\prime} \mathrm{S}, 37^{\circ} 15^{\prime} \mathrm{W}$ ) está situada no município de Serra Negra do Norte, ocupando uma área de 1166,38ha e compreende uma região de caatinga hiperxerófila. A vegetação local enquadra-se na fitofisionomia arbóreo-arbustiva, e apresenta um estrato herbáceo onde predominam gramíneas de vários tipos, de acordo com a constituição do solo (Varela-Freire 2002). Os solos predominantes são os litossolosvermelho-amarelos (solos rasos e pedregosos), que se tratam de aluviões e planícies sedimentares, e os vertissolos (massapés), profundos e escuros (VarelaFreire 2002).

\section{VALE DOAÇU}

A microrregião do Vale do Açu situa-se na ecorregião da Depressão Sertaneja Setentrional (Velloso et al. 2001) e possui clima quente semiárido típico da Caatinga. O período chuvoso, ocorre geralmente, entre outubro e abril, sendo as chuvas mais concentradas do que no restante do bioma. A ocorrência de períodos secos prolongados apresentase de forma mais comum nesta região. A pluviosidade local fica em torno de 500 e $800 \mathrm{~mm}$ (Velloso et al. 2001). Os solos locais são predominantemente dos tipos podzólicos, litólicos e planossolos (Velloso et al. 2001). A altitude varia de 20 a $500 \mathrm{~m}$ nas depressões, com elevações de 500 a $800 \mathrm{~m}$. Apresenta vegetação do tipo caatinga arbustiva-arbórea, com ocorrência de caatinga arbórea nos sopés de encostas e serras baixas, embora a grande maioria se encontre muito degradada (Velloso et al. 2001). 


\section{Floresta Nacional de Açu}

A Floresta Nacional de Açu (FLONA de Açu) (05³4'S; 36 $56^{\circ}$ 'W) localiza-se no município de mesmo nome no Estado do Rio Grande do Norte. Possui uma área de 215 ha com vegetação típica de Caatinga e fitofisionomia arbóreo-arbustiva densa (IBAMA 2005), embora algumas partes estejam descaracterizadas por plantações de árvores frutíferas. O solo é arenoso na maior parte da área, com alguns locais de solo argiloso raso com pequenas extrusões de rochas. Em vários locais, tanto em solos argilosos quanto em arenosos, pode-se notar a presença de cascalho (rochas pequenas soltas); também é notável a ausência de grandes afloramentos rochosos, muito comum em algumas localidades na Caatinga.

A área nos arredores da Lagoa do Piató, situada no limite norte desta FLONA, possui solo arenoso, alternado por solo argiloso a uma distância de aproximadamente $100 \mathrm{~m}$ da margem da lagoa. A vegetação neste local é muito esparsa devido ao desmatamento localizado (IBAMA, comunicação pessoal).

\section{MATERIAL E MÉTODOS}

Foram realizadas 13 excursões entre janeiro de 2004 e abril de 2005 assim distribuídas: seis excursões à área de São João do Cariri, três à RPPN Fazenda Almas (ambas no estado da Paraíba); três à Estação Ecológica do Seridó, e uma à Floresta Nacional de Açu (estas últimas no estado do Rio Grande do Norte). As coletas totalizaram 383 horas/coletor.

Durante as excursões foram realizadas buscas ativas e intensivas nos mais diversos locais e tomadas notas sobre as características dos hábitats e microhábitats onde os espécimes foram coletados (características do solo local, tipo de vegetação e se o local encontrava-se sombreado ou ensolarado).

Devido à variação ocorrente na espécie, o padrão de coloração em vida para Vanzosaura rubricauda também foi registrado para cada indivíduo. Foram considerados três padrões baseados em observações de Vanzolini et al. (1980) e Vitt (1982): padrão simples, apresentando uma linha branca que se estende do supercílio à raiz da cauda na face dorso-lateral do corpo, sendo esta e sua simétrica entremeadas por uma área olivácea de reflexos metálicos; padrão complexo, que consiste de uma alternação de seis linhas claras em cada hemi-dorso, separadas por áreas escuras, ocasionalmente manchadas por pontos claros; e padrão de coloração intermediária, apresentando de duas (2) a cinco (5) linhas em cada hemi-dorso, sendo a região médio-dorsal do indivíduo de cor semelhante a apresentada pelos espécimes de padrão simples de coloração. Estes dados foram utilizados para análises taxonômicas das populações.

O material coletado foi tombado na Coleção Herpetológica do Departamento de Botânica, Ecologia e Zoologia da Universidade Federal do Rio Grande do Norte - DBEZ (material obtido no Rio Grande do Norte) e na Coleção Herpetológica do Departamento de Sistemática e Ecologia da Universidade Federal da Paraíba - DSE (material coletado neste estado).

A identificação foi realizada com base nos trabalhos de Boulenger (1902), Amaral (1933, 1934, 1935, 1937), Dixon (1974), Vanzolini et al. (1980), Rodrigues (1991a, 1991b, 1991c), Queiroz \& Lema (1996), Rodrigues et al. (2001) e complementada pela comparação com exemplares previamente depositados nas coleções herpetológicas do DBEZ e do DSE.

Além dos exemplares obtidos neste estudo, também foram analisados mais dois exemplares da espécie $A$. vanzolinia, provenientes do município de São José da Mata, estado da Paraíba, e três exemplares da espécie V. rubricauda, sendo dois de Campo do Amaro (área pertencente à PETROBRÁS), município de Mossoró, e um do município de Monte Alegre, ambos no estado do Rio Grande do Norte.

As localidades onde cada espécie foi coletada, além das localidades de ocorrência conhecidas anteriormente para Anotosaura vanzolinia, foram demarcadas em mapa dos estados da Paraíba e do Rio Grande do Norte. Este mapa foi comparado com aqueles disponíveis no trabalho de Rodrigues (1995) para avaliar a distribuição geográfica conhecida para os gimnoftalmídeos na Caatinga nordestina.

\section{RESULTADOS E DISCUSSÃO}

Durante as 383 horas-homem de trabalho de campo, foram registradas quatro espécies de lagartos da família Gymnophthalmidae: Anotosaura vanzolinia Dixon 1974, Acratosaura mentalis Amaral 1933, Micrablepharus maximiliani (Reinhardt \& Lütken 1862) e Vanzosaura rubricauda (Boulenger 1902). 


\section{LISTA COMENTADA DAS ESPÉCIES}

\section{- Anotosaura vanzolinia Dixon 1974 (Figura 1A)}

Localidade-tipo: Agrestina, estado de Pernambuco, Brasil.

Distribuição Geográfica: Agrestina e Serra Negra, estado de Pernambuco; Cabaceiras, estado da Paraíba (Rodrigues 1986b). Novos registros para o município de São José da Mata $\left(07^{\circ} 11^{\prime} 00^{\prime \prime}\right.$, 35 35 58'30”W) e para a RPPN Fazenda Almas, municípios de São José dos Cordeiros/Sumé, ambos no estado da Paraíba (Figura 2).

História Natural: Esta espécie parece preferir ambientes de clima mais ameno que o da caatinga típica. Agrestina está situada na faixa transicional conhecida como 'agreste' (Vanzolini \& Ramos 1977); em Serra Negra, a espécie foi obtida em um relicto de mata úmida. Deste modo, apenas Cabaceiras encontra-se situada em uma área de caatinga. Neste local, a espécie foi coletada na base de um serrote pedregoso, com árvores altas que permanecem verdes o ano todo (Rodrigues 1986b). Os exemplares coletados na área da RPPN Fazenda Almas foram encontrados em local muito semelhante ao descrito por Rodrigues (1986b), onde havia muita serrapilheira úmida acumulada no solo (Tabela I). Quando avistados, os indivíduos tentavam se enterrar ou fugir por entre as pedras soltas muito comuns no local. Os exemplares obtidos na área de São José da Mata foram encontrados no interior de um cupinzeiro.

Descrição do material obtido: foram coletados seis exemplares na RPPN Fazenda Almas, e mais dois exemplares foram obtidos de terceiros, provenientes da região de São José da Mata, ambas as localidades no estado da Paraíba. Dentre os caracteres selecionados alguns apresentaram variação em relação aos números encontrados por Dixon (1974). O número de escamas dorsais dos exemplares coletados não concordou com a descrição da espécie, variando entre 26 e 29 escamas, enquanto o encontrado por Dixon (1974) ficou entre 30 e 32. As contagens encontradas nos exemplares obtidos neste estudo concordam e/ou ficam mais próximos do relatado para Anotosaura collaris, o outro representante do gênero, que é conhecido de Senhor do Bonfim, no estado da Bahia. Os outros caracteres averiguados ( $4^{\circ}$ dedo mais longo, $3^{\circ} \mathrm{em}$ A. collaris; e ausência de pré-frontais, presentes nesta última espécie) diagnosticam os exemplares obtidos como A. vanzolinia. Outros caracteres que apresentaram variação foram os números de infralabiais e o de escamas ao redor do corpo, que apresentaram pequenas variações. Alguns exemplares apresentaram seis infralabiais no lado esquerdo da cabeça (normalmente encontradas em número de cinco), com a terceira escama dividida em duas; enquanto que o número de escamas ao redor do corpo variou entre 25 a 28 (25 a 26 na diagnose da espécie citada por Dixon 1974). Apesar disto, o autor cita que alguns indivíduos apresentaram uma variação que ficou entre 23 a 25 escamas ao redor do corpo. Os outros caracteres enquadraram-se dentro dos padrões citados para a espécie. Apesar das variações encontradas na escamação de alguns indivíduos, foi mantida a identificação como A. vanzolinia.

- Acratosaura mentalis (Amaral 1933) (Figura 1B)

Localidade-tipo: Villa Nova $(=$ Senhor do Bonfim), estado da Bahia, Brasil.

Distribuição Geográfica: De acordo com Rodrigues (1986b), a espécie possui distribuição disjunta sendo encontrado em Senhor do Bonfim, estado da Bahia; Grão Mogol na Serra do Espinhaço, estado de Minas Gerais; Cabaceiras, estado da Paraíba. Também ocorre em Xingó, estados de Alagoas/Sergipe (Bandeira 2000), Brejo da Madre de Deus, estado de Pernambuco (Queiroz \& Lema 1996) e Cacimba de Dentro, estado da Paraíba (Arzabe et al. 2005). Queiroz \& Lema (1996) enquadram a espécie como típica da região de agreste do nordeste do Brasil, ampliando sua distribuição para toda esta região da Paraíba até Bahia. A espécie teve novo registro no estado da Paraíba, para a área da RPPN Fazenda Almas, municípios de Sumé e São José dos Cordeiros (Figura 2).

História Natural: assim como A. vanzolinia, esta espécie parece ser encontrada principalmente em locais de clima mais ameno. Acratosaura mentalis parece estar intimamente ligada a áreas onde ocorrem fácies típicas de Cerrado, campos rupestres e/ou caatinga, sendo encontrada principalmente em locais com enclaves destes tipos de vegetação (Rodrigues 1986b). Os exemplares coletados em Cabaceiras por Rodrigues (1986b) encontravam-se no mesmo local dos espécimes de A. vanzolinia. Este fato se repetiu 
na RPPN Fazenda Almas, onde também foram encontrados em sintopia (Tabela I). Dois dos exemplares obtidos encontravam-se enterrados na serrapilheira entre as extrusões rochosas do local. Quando avistados tentavam correr para as pequenas fendas existentes entre estas rochas. $\mathrm{O}$ outro exemplar coletado foi encontrado sob um pequeno pedaço de tronco no chão em baixo de um umbuzeiro (Spondias tuberosa), onde havia muito folhiço acumulado. Quando exposto, enterrou-se rapidamente e permaneceu imóvel por alguns minutos até ser encontrado novamente.

Descrição do material obtido: foram coletados três exemplares da espécie, todos provenientes da RPPN Fazenda Almas, Paraíba. Todos os caracteres examinados concordaram com os encontrados por Amaral (1933) na descrição da espécie e com os exemplares examinados por Queiroz \& Lema (1996).

- Micrablepharus maximiliani (Reinhardt \& Lutken 1862) (Figura 1C)

Localidade-tipo: Brasil.

Distribuição Geográfica: doMaranhãoaoParaguai, em formações abertas, incluindo o Cerrado, o Pantanal, a Caatinga, atingindo até regiões de restingas costeiras do nordeste do Brasil (Peters \& Donoso-Barros 1970, Vanzolini et al. 1980, Rodrigues 1995, 1996a, Freire 1996, Colli et al. 2002). A localidade registrada para a espécie no presente estudo está inserida dentro da distribuição já conhecida para a mesma (Figura 2).

História Natural: Apesar de ser tratada como sendo amplamente distribuída nas formações vegetais abertas da América do Sul (Rodrigues 1996a), a espécie parece não habitar a caatinga mais rústica, sendo encontrada em ambientes de clima mais amenos (Vanzolini et al. 1980), tendo sido capturada, inclusive, em ambientes de floresta atlântica (Vanzolini et al. 1980, Rodrigues 1995, Freire 1996, Colli et al. 2002). Segundo Rodrigues (1995) a espécie procura refúgio enterrando-se no solo arenoso, fato este que pode limitar sua ocorrência a locais que apresentem tal tipo de solo. Apenas uma muda de pele da espécie foi obtida na área da FLONA de Açu, em um local de solo arenoso ao redor da Lagoa do Piató. O local tinha muito folhiço sob uma árvore e estava bem sombreado (Tabela I).

Descrição do material obtido: a identificação da espécie foi possível devido às boas condições de preservação da muda de pele obtida, onde foi possível observar a presença de escamas fronto-parietais (ausentes em $V$. rubricauda), ausência de pré-frontais (presentes em $V$. rubricauda e nos lagartos do gênero Mabuya), pelo número de supra e infralabiais (geralmente mais elevado nos lagartos do gênero Mabuya) e pela organização das escamas mentais e gulares (Vanzolini et al. 1980, Rodrigues 2000).

- Vanzosaura rubricauda (Boulenger, 1902) (Figura 1D)

Localidade-tipo: Senhor do Bonfim, estado da Bahia, Brasil.

Distribuição Geográfica: Ao longo de toda a diagonal de formações vegetais abertas da América do Sul. Na Caatinga, distribui-se de Baturité, no Ceará, até Senhor do Bonfim, na Bahia (Vanzolini et al. 1980, Rodrigues 1991c, Rodrigues 1995). As localidades onde a espécie foi obtida neste estudo encontram-se dentro de sua área de distribuição conhecida (Figura 2).

História Natural: é a espécie de gimnoftalmídeo da Caatinga mais amplamente distribuída, ocorrendo também no Cerrado. Possui, consequentemente, uma distribuição ecológica bastante ampla. Distribui-se em todo o bioma, nas mais diversificadas fitofisionomias. É encontrada principalmente em locais com acúmulo de serrapilheira no solo, em capinzais ralos e outras áreas com pouca cobertura de vegetação. Segundo Vanzolini et al. (1980) "é um lagartinho bem generalista quanto às localidades de caatinga que habita".

Os exemplares coletados durante este estudo demonstraram claramente suas preferências ecológicas, sendo quase a totalidade encontrada em locais com muito folhiço acumulado no solo (Tabela I). Alguns poucos exemplares $(n=5)$ foram coletados em locais expostos, quando provavelmente tentavam passar de um local para outro para se refugiar novamente. Em locais onde ocorrem muitas cactáceas, como em São João do Cariri, estes lagartos parecem preferir como refúgio touceiras deste tipo de planta, principalmente entre os xique-xiques (Pilosocereus gounellei), tendo em vista que a maioria $(n=31)$ foi encontrada nestes microhábitats. Quando avistados procuravam se enterrar (em localidades de solo arenoso ou não compactado) ou refugiar-se em baixo das folhas mais próximas.

Descrição do material obtido: foram analisados 98 exemplares da espécie, sendo 43 de São João do Cariri; 20 da RPPN Fazenda Almas; 16 da ESEC 
do Seridó; 16 da FLONA de Açu. Além de três exemplares da espécie provenientes de Campo do Amaro (área pertencente à PETROBRÁS), município de Mossoró e um do município de Monte Alegre, ambos no estado do Rio Grande do Norte. Poucas variações nos caracteres foram encontradas, não sendo nenhuma comprometedora na identificação dos exemplares. Como relatado por vários autores, a condição de contato entre as pré-frontais varia de uma condição de amplo contato na linha mediana até a separação devido ao contato entre a frontal e a fronto-nasal (Boulenger 1902 - separadas; Amaral 1933 - em contato mediano, 1935 - separadas, Rodrigues 1991c - ambas as condições). Vinte e seis exemplares apresentam as pré-frontais separadas. A condição foi observada em exemplares de São João do Cariri ( $\mathrm{n}=14)$, RPPN Fazenda Almas ( $\mathrm{n}=4)$, ESEC do Seridó $(\mathrm{n}=7)$ e FLONA de Açu $(\mathrm{n}=1)$. O número de supra e infralabiais também discordou em relação ao número encontrado por Vanzolini et al. (1980). Estes autores citam um número de seis supralabiais e cinco infralabiais, enquanto no presente estudo foram contabilizadas sempre sete supralabiais e a variação entre cinco e sete infralabiais. $O$ caso parece não passar de um pequeno engano por parte dos autores, já que em seu livro 'Répteis das Caatingas' eles fornecem um desenho esquemático desta e de outra espécie de gimnoftalmídeo registrada para o bioma, Micrablepharus maximiliani. Nestes desenhos é possível observar que os autores desconsideraram a última supralabial na contagem para $V$. rubricauda, enquanto que na outra espécie, a escama correspondente foi contabilizada (Anexo I). Boulenger (1902) e Amaral (1934) encontraram sete escamas supralabiais para a espécie, concordando com o número obtido nos exemplares analisados durante o presente trabalho. O número de infralabiais apresentou uma variação dentro do encontrado por outros autores, apesar das citações de números fixos pelos autores (Vanzolini et al. 1980 citam cinco, Amaral 1934 cita sete ao invés de cinco).

Vanzolini et al. (1980) e Vitt (1982), citam dois tipos de padrão de coloração dorsal para $V$. rubricauda: um padrão simples, apresentando uma linha branca que se estende do supercílio à raiz da cauda na face dorso-lateral do corpo, sendo esta e sua simétrica entremeadas por uma área olivácea de reflexos metálicos, abaixo da linha branca existe uma área esfumaçada percorrida por outra linha clara interrompida, com uma área mosqueada abaixo desta diluindo-se no abdômen (Figura 1F); e um padrão complexo, que consiste de uma alternação de seis linhas claras em cada hemi-dorso, separadas por áreas escuras, ocasionalmente manchadas por pontos claros (Figura 1D). Foram coletados exemplares apresentando ambos os padrões, mas alguns apresentaram uma coloração intermediária entre estas, apresentando de duas a cinco linhas em cada hemidorso, sendo a região médio-dorsal do indivíduo de cor semelhante ao apresentado pelos espécimes de padrão simples de coloração (Figura 1E). Os exemplares de padrão simples e intermediário mostraram-se muito abundantes em localidades que possuíam solo arenoso (Figura 3), enquanto que em localidades com solo argiloso mais duro foram raramente observados. O caráter pode estar relacionado a características da vegetação local que deve variar quanto ao tipo de solo, atuando assim na seletividade natural dos indivíduos. Rodrigues (1991c) tratou de aspectos da coloração de Vanzosaura rubricauda, embora tenha se detido à coloração da cauda, comparando-a com as espécies dos gêneros Procellosaurinus e Gymnophthalmus. Portanto, esta variação no colorido dorsal é algo que ainda não foi estudado com detalhes, sendo necessários estudos mais direcionados para se poder concluir algo mais seguro sobre sua possível relação com 'mecanismos' seletivos existentes.

AS QUATRO ESPÉCIES DE GIMNOFTALMÍDEOS E SUAS RESPECTIVAS DISTRIBUIÇÕES GEOGRÁFICAS

Das quatro espécies de lagartos da família Gymnophthalmidae registradas neste estudo (Tabela II), Anotosaura vanzolinia e A. mentalis foram encontradas apenas na área da RPPN Fazenda Almas, única localidade com caatinga arbórea densa. Anotosaura vanzolinia também foi obtida por terceiros na região de São José da Mata, PB (Figura 1). Os resultados obtidos corroboram o estado atual do conhecimento em relação à distribuição destes lagartos, com exceção de um novo registro de ocorrência para $A$. vanzolinia e A. mentalis no Estado da Paraíba.

Rodrigues (1995, 2003), quando discute os padrões de distribuição e a história geográfica de lagartos gimnoftalmídeos sem pálpebras, afirma que, 

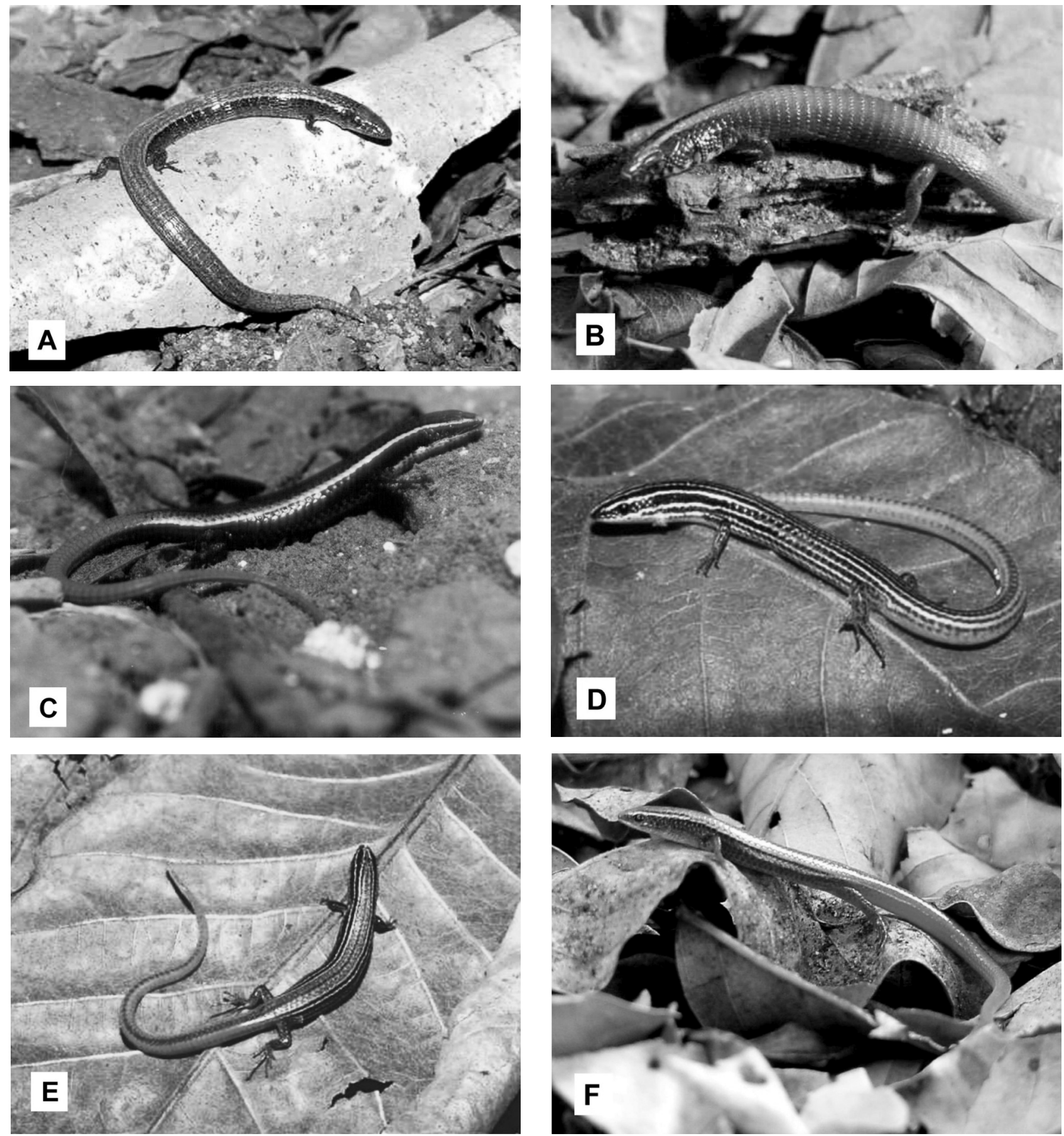

Figura 1. Lagartos da família Gymnophthalmidae registradas durante o presente estudo, entre janeiro de 2004 e abril de 2005. A-Anotosaura vanzolinia - Fazenda Almas, São José dos Cordeiros/Sumé, Paraíba; B - Acratosaura mentalis - Fazenda Almas; C - Micrablepharus maximiliani; D a F Vanzosaura rubricauda (D - padrão complexo de coloração - São João do Cariri, Paraíba; E - padrão intermediário de coloração - Fazenda Almas; F - padrão simples de coloração - FLONA de Açu, Rio Grande do Norte) (Fotos: A, B, D, E e F - Fagner Delfim; C - Yuri Lima). 


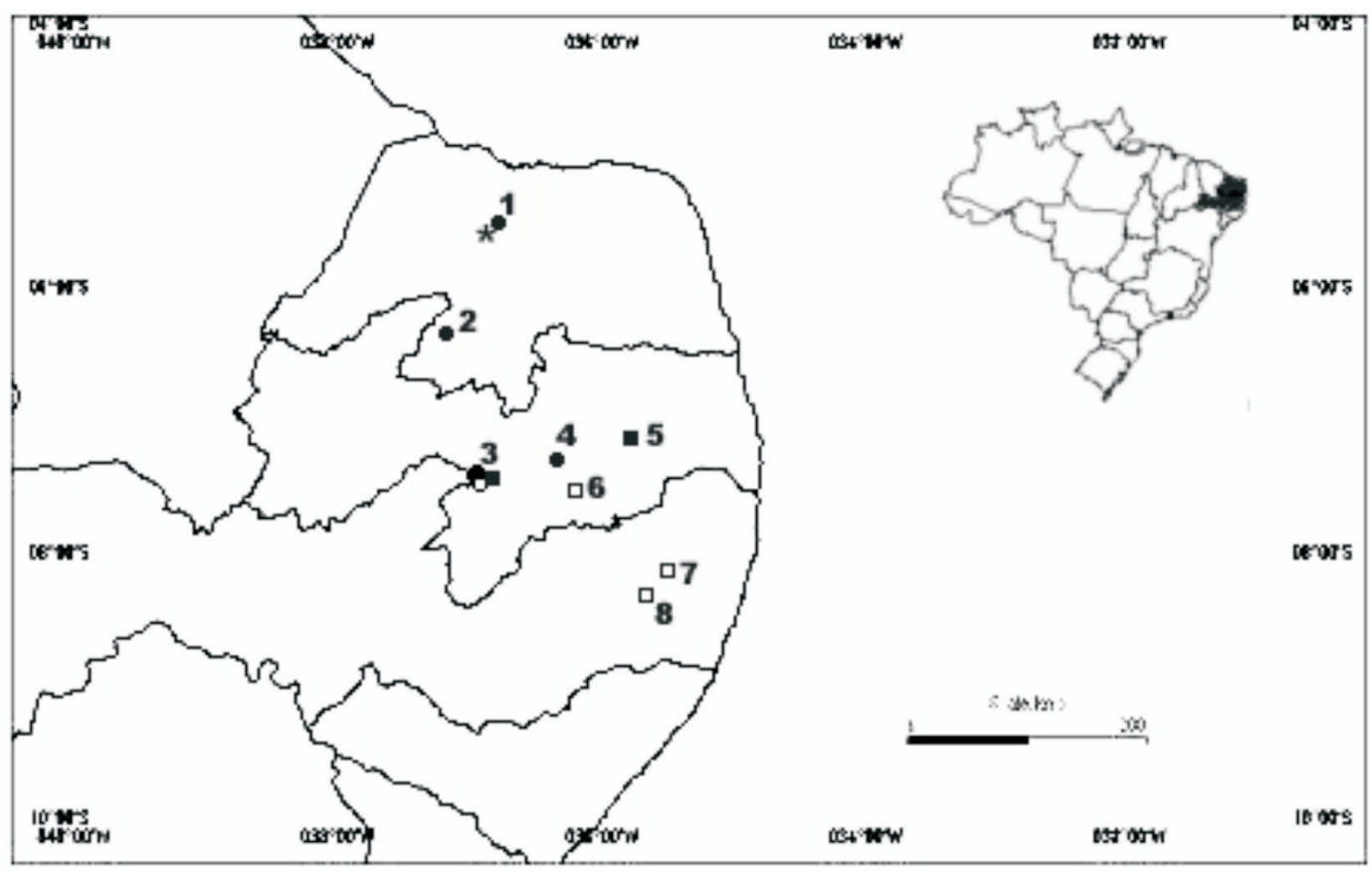

Figura 2. Distribuições das áreas amostradas no estudo de inventário dos lagartos da família Gymnophthalmidae. Inclui-se a distribuição anteriormente conhecida para a espécie Anotosaura vanzolinia. 1 - FLONA de Açu, município de Açu - RN; 2 - ESEC Seridó, município de Serra Negra do Norte - RN; 3 - RPPN Fazenda Almas, municípios de São José dos Cordeiros / Sumé - PB; 4 - São João do Cariri - PB; 5 - São José da Mata - PB; 6 Cabaceiras - PB; 7 - Serra Negra - PE; 8 - Agrestina - PE. ¡\% (quadrado vazio) - Anotosaura vanzolinia - distribuição conhecida para a espécie; \% (quadrado preenchido) - A. vanzolinia - novos pontos de coleta; Ё\% (círculo vazio) - Acratosaura mentalis; *(estrela) - Micrablepharus maximiliani; Ï\% (círculo preenchido) - Vanzosaura rubricauda.
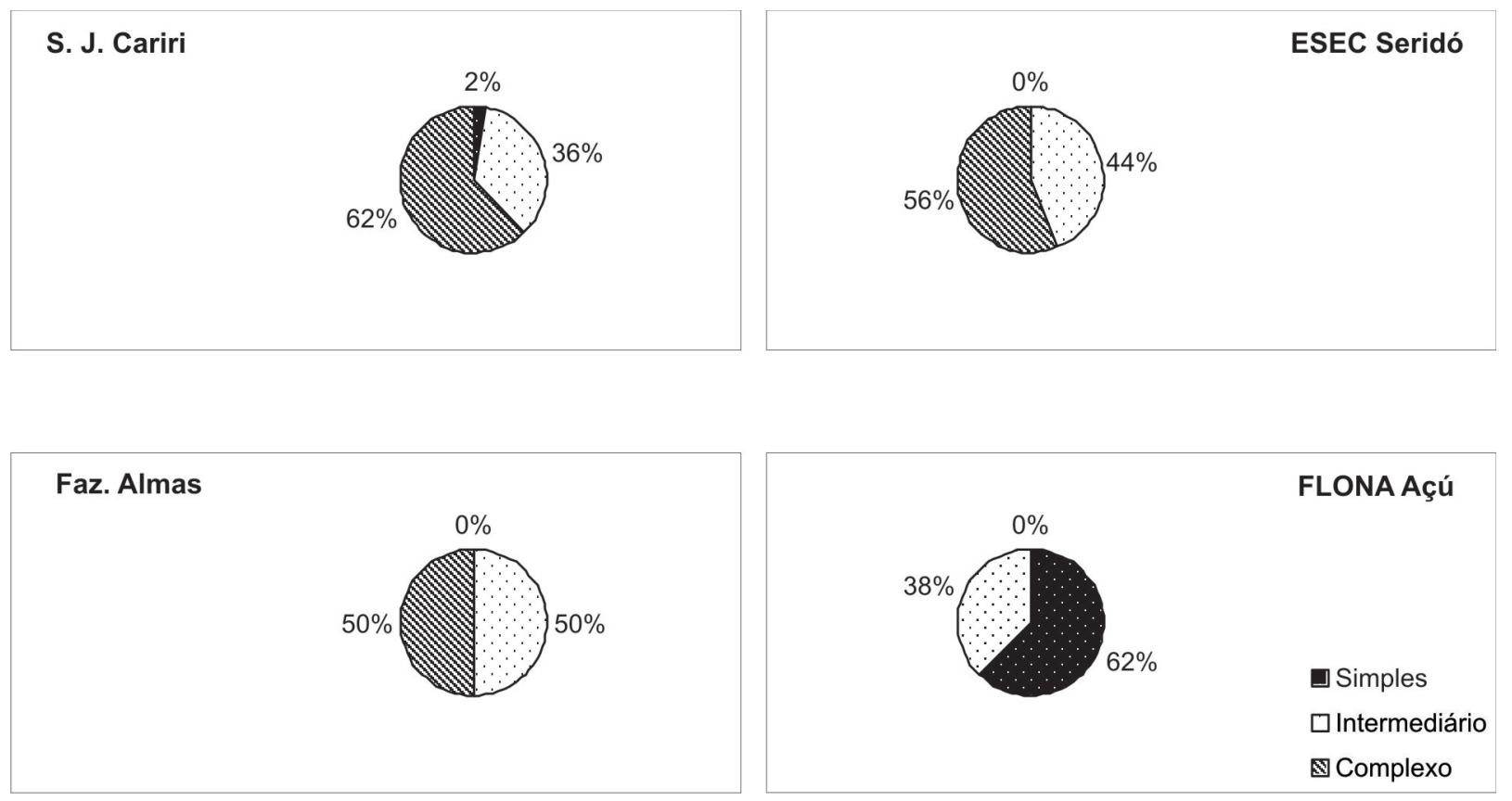

Figura 3. Gráficos demonstrando as abundâncias relativas dos padrões de coloração encontrados em Vanzosaura rubricauda por localidade de coleta São João do Cariri (solo argiloso); Fazenda Almas (poucas áreas arenosas); ESEC do Seridó (solo argiloso); FLONA de Açu (maior parte arenosa). 


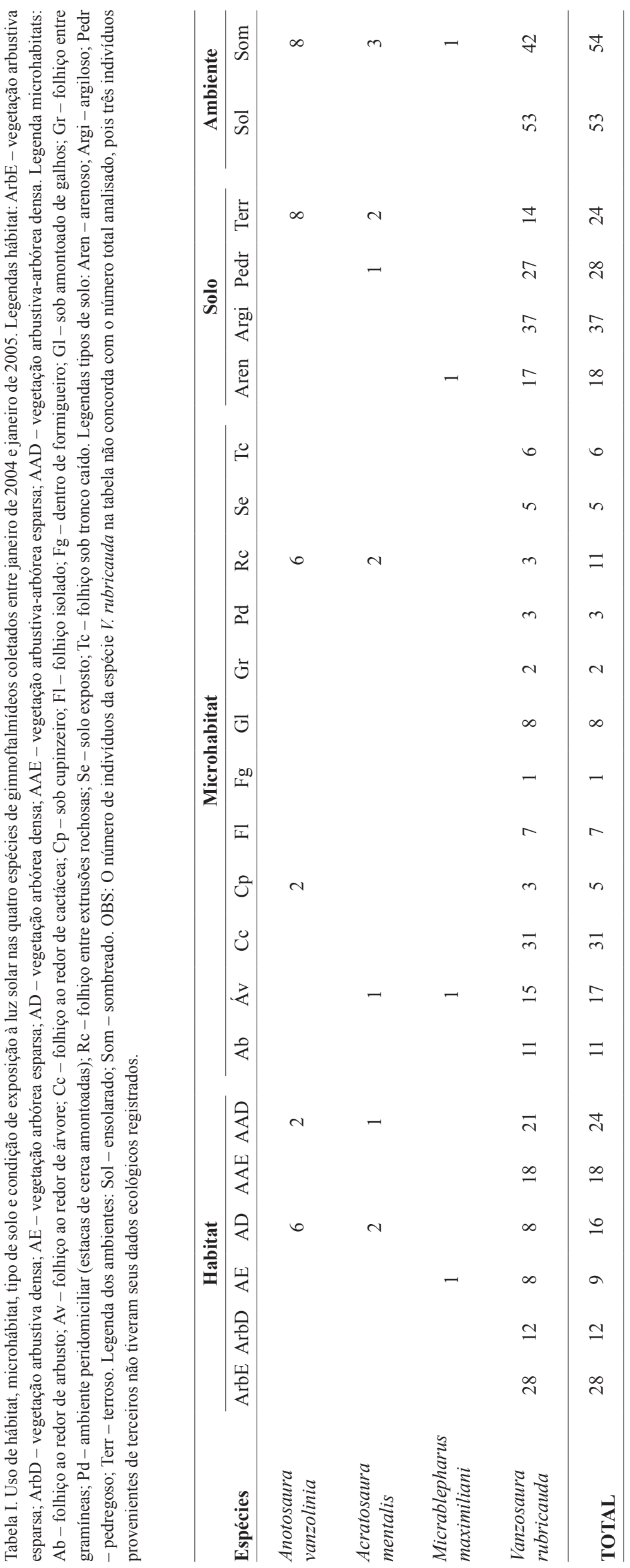


Micrablepharus maximiliani e Vanzosaura rubricauda são os únicos que se distribuem amplamente na Caatinga; os outros lagartos deste ramo (Gymnophthalmini) têm sua história geográfica ligada aos campos de dunas do Rio São Francisco (Tabela III). Micrablepharus distribui-se principalmente nas regiões nucleares dos Domínios do Cerrado e da Caatinga (Rodrigues 1995, 1996a); Micrablepharus maximiliani, distribui-se no Cerrado, Pantanal e Caatinga, atingindo até regiões de restingas costeiras do nordeste do Brasil (Rodrigues 1995, Freire 1996, Colli et al. 2002). Pode também ser encontrado em ambientes florestados, embora sempre relacionados a clareiras ou ambientes abertos que circundam as mesmas (Borges-Nojosa \& Caramaschi 2003). Esta espécie, entretanto, não foi coletada em nenhuma localidade; foi apenas registrada na área da FLONA de Açu, devido ao encontro de uma muda de pele em bom estado de conservação.

Vanzosaura rubricauda distribui-se amplamente pela grande diagonal cis-andina de formações vegetais abertas da América do Sul (Gallardo 1969, Vanzolini et al. 1980, Rodrigues 1991c, 1995); na Caatinga, distribui-se de Baturité, no estado do Ceará, até Senhor do Bonfim, estado da Bahia (Vanzolini et al. 1980).

O registro destas duas espécies nas localidades exploradas (Figura 2) confirma as propostas existentes sobre suas distribuições geográficas (Rodrigues 1995).

Anotosaura vanzolinia distribui-se de forma disjunta na Caatinga, possuindo registros de ocorrência apenas em três localidades (Figura 2 - pontos 6, 7 e 8) (Dixon 1974, Vanzolini 1976, Rodrigues 1986b). Entretanto, devido aos hábitos crípticos e fossoriais da espécie, é possível evocar deficiências de amostragem em outros inventários realizados em localidades onde possivel- mente a espécie seja ocorrente. Apenas após novas e intensivas coletas ao longo de todo o Bioma Caatinga, será possível avaliar a situação real desta espécie.

A espécie Acratosaura mentalis parece estar intimamente ligada a áreas onde ocorrem fácies típicas de Cerrado, campos rupestres e/ou caatinga, embora seja mais encontrada em locais com enclaves destes tipos de vegetação (Rodrigues 1986b). Queiroz \& Lema (1996), com base apenas nos registros da espécie em Senhor do Bonfim, Bahia e Cabaceiras, Paraíba, mais o novo registro para Brejo da Madre de Deus no estado de Pernambuco, ampliam a distribuição da espécie para todo o distrito oriental do Nordeste do Brasil, enquadrando-a fisionomicamente na Região do Agreste nordestino. A hipótese defendida por estes autores não apresenta resultados suficientes para torná-la confiável, pois parece prematuro ampliar a distribuição de A. mentalis baseando-se somente em três localidades onde a espécie foi registrada.

Rodrigues $(1986 \mathrm{~b}, 2003)$ considera que $A$. vanzolinia e $A$. mentalis possuem populações de distribuição disjunta, de caráter relictual na Caatinga, sendo encontradas apenas em locais mais mésicos do que nas áreas mais rústicas deste bioma. Este fato é corroborado por resultados obtidos durante este trabalho, quando ambas as espécies foram coletadas apenas na RPPN Fazenda Almas, localidade com vegetação arbórea e clima mais ameno que as demais. Estas foram encontradas principalmente em locais na base dos serrotes pedregosos, onde ocorre um maior acúmulo de serrapilheira, apresentando vegetação arbórea mais densa e maior umidade. Segundo Rodrigues (1986b), as duas espécies foram coletadas em locais muito semelhantes na Fazenda Bravo, município de Cabaceiras, Estado da Paraíba.

Tabela II. Lista das espécies coletadas por localidade, nos estados da Paraíba e do Rio Grande do Norte, Brasil, entre janeiro de 2004 e janeiro de 2005.

\begin{tabular}{|c|c|c|c|c|}
\hline Localidade & $\begin{array}{c}\text { São João do Cariri } \\
\text { - PB }\end{array}$ & $\begin{array}{c}\text { RPPN Faz. Almas } \\
- \text { PB }\end{array}$ & ESEC do Seridó - RN & FLONA de Açu - RN \\
\hline \multicolumn{5}{|l|}{ Espécie } \\
\hline Anotosaura vanzolinia & & $\mathrm{X}$ & & \\
\hline Acratosaura mentalis & & $X$ & & \\
\hline Micrablepharus maximiliani & & & & $\mathrm{X}$ \\
\hline Vanzosaura rubricauda & $\mathrm{X}$ & $X$ & $\mathrm{X}$ & $\mathrm{X}$ \\
\hline
\end{tabular}


Durante outras coletas realizadas no estado da Paraíba, também foram obtidos exemplares da espécie Acratosaura mentalis, tanto no Parque Estadual Pedra da Boca - PEPB, situado no município de Araruna, quanto na Fazenda Cachoeira da Capivara, no município de Cacimba de Dentro (Arzabe et al. 2005). O PEPB está localizado numa região considerada por Ab'Saber (2003) como uma área de transição entre áreas mamelonares tropical-atlânticas florestadas e depressões intermontanas e interplanálticas semiáridas (Caatingas). Sofrendo forte influência atlântica, o local apresenta características climáticas muito mais mésicas do que o restante das localidades na Caatinga (Arzabe et al. 2005), corroborando a hipótese de Rodrigues (1986b, 2003) para a distribuição desta espécie. A Fazenda Cachoeira da Capivara apresenta, por sua vez, características muito mais típicas de Caatinga, apresentando uma vegetação arbustivoarbórea dominante. Apesar disso, as contínuas touceiras de bromeliáceas existentes no local parecem formar um micro-ambiente mais protegido e de clima mais ameno do que nos arredores devido ao acúmulo de água entre suas folhas (Rocha 2000), fornecendo condições propícias para lagartos com maiores exigências ecológicas, como no caso de $A$. mentalis (Rodrigues 1986b). A localidade onde esta espécie foi encontrada em Xingó, também parece favorecer sua ocorrência. Os exemplares da espécie foram coletados em ambas as margens do Rio São Francisco, nos estados de Alagoas e Sergipe, que também possuíam características favoráveis às exigências ecológicas destes lagartos (Bandeira 2000).

Todas as outras espécies listadas por Rodrigues (2003), que apresentam distribuições de caráter relictual, são pertencentes a gêneros relacionados à $A$. mentalis e A. vanzolinia, que parecem ter biologia e ecologia semelhantes. Além disso, estão relacionadas a brejos de altitude localizados na Caatinga (Borges-Nojosa \& Caramaschi 2003), ou a locais que possuem condições mais mésicas que outras localidades (Dixon 1974, Vanzolini \& Ramos 1977). Vanzolini \& Ramos (1977) propuseram em seu trabalho que estes microteíideos têm suas distribuições encalhadas (stranded), encontrandose em situações marginais heterogêneas, sem condições mais favoráveis para sua expansão. É muito provável que estas espécies tenham suas distribuições atuais definidas pelas expansões e retrações das florestas úmidas e da caatinga, ficando atualmente restritas a ambientes que conservaram características favoráveis à existência das mesmas (Rodrigues 1995, 2003, Vanzolini 1981, Vanzolini \& Williams 1981).

Parece prematuro considerar a distribuição de

Tabela III. Lista das espécies e seus respectivos padrões de distribuição na Caatinga do nordeste do Brasil (modificado de Rodrigues 2003). (AO) espécies de ampla ocorrência no domínio das Caatingas; (R) espécies de distribuição com caráter relictual; (DSF) espécies cuja distribuição está ligada às dunas do Rio São Francisco ou áreas adjacentes que tiveram ou têm ligação passada com aquelas dunas. *Espécie com registro adicionado por Borges-Nojosa \& Cascon (2005).

\begin{tabular}{lc}
\hline Espécie & Padrão de distribuição \\
\hline Anotosaura vanzolinia Dixon, 1974 & $R$ \\
Anotosaura collaris Amaral, 1933 & $R$ \\
Calyptommatus confusionibus Rodrigues, Zaher \& Curcio, 2001 & $D S F$ \\
Calyptommatus leiolepis Rodrigues, 1991 & $D S F$ \\
Calyptommatus nicterus Rodrigues, 1991 & $D S F$ \\
Calyptommatus sinebrachiatus Rodrigues, 1991 & $D S F$ \\
Acratosaura mentalis Amaral, 1933 & $R$ \\
Colobosaura modesta (Reinhardt \& Lütken, 1862)* & \\
Colobosauroides cearensis Cunha, Lima-Verde \& Lima, 1991 & $R$ \\
Colobosauroides carvalhoi Soares \& Caramaschi, 1998 & $R$ \\
Micrablepharus maximiliani (Reinhardt \& Lütken, 1862) & $R$ \\
Notobachia ablephara Rodrigues, 1984 & $R$ \\
Procellosaurinos erythrocercus Rodrigues, 1991 & $A O$ \\
Procellosaurinos tetradactylus Rodrigues, 1991 & $D S F$ \\
Psilophthalmus paeminosus Rodrigues, 1991 & $D S F$ \\
Vanzosaura rubricauda (Boulenger, 1902) & $D S F$
\end{tabular}


alguns destes gimnoftalmídeos, como de caráter relictual, pois com a intensificação de coletas e conseqüente ampliação da cobertura das áreas na Caatinga, será possível descobrir se estas espécies distribuemse de forma mais ampla do que é proposto.

Rodrigues (2003) comenta ainda que, não só com relação aos gimnoftalmídeos, mas em relação a herpetofauna em geral, os principais endemismos estão relacionados a solos arenosos (Rodrigues 1984a, 1984b, 1986c, 1991a, 1991b, 1991c, 1992, 1993, 1995, 1996b, Rodrigues et al. 1988, Vanzolini 1991a, 1991b). Devido a este fato, a existência de um número tão superior de lagartos da família Gymnophthalmidae na região das dunas do Rio São Francisco quando comparadas a outras localidades na Caatinga (Tabela III) pode ser explicada. Mesmo com algumas propostas de endemismos tendo sido descaracterizadas (Delfim et al. 2006, Rodrigues et al. 2001), é muito clara a relação entre as localidades onde Psilophthalmus e Calyptommatus foram coletados posteriormente e o campo de dunas do Estado da Bahia (Oliveira et al. 1999, Rodrigues et al. 2001).

Não se pode, entretanto, descartar a hipótese de existência de outras espécies de gimnoftalmídeos na Caatinga, em regiões ainda não amostradas. Um exemplo disto é o recente registro de Colobosaura modesta na região de Serra das Almas no estado do Ceará, região de brejo de altitude (Borges-Nojosa \& Cascon 2005).

\section{REFERÊNCIAS}

AB'SABER, A.N. 1967. Domínios morfoclimáticos e províncias fitogeográficas do Brasil. Orientação (Departamento de Geografia/USP), 3: 45-48.

AB'SABER, A.N. 1969. Participação das superfícies aplainadas nas paisagens do nordeste brasileiro. Geomorfologia, 19: 1-19.

AB'SABER, A.N. 1974. O domínio morfoclimático semi-árido das Caatingas brasileiras. Geomorfologia, 43: 1-39.

AB'SABER, A.N. 2003. Os domínios de Natureza no Brasil: potencialidades paisagísticas. São Paulo: Ateliê Editorial.

AMARAL, A. 1933. Estudos sobre os Lacertílios Neotrópicos: Novos Gêneros e Espécies de lagartos do Brasil. Memórias do Instituto Butantan, 7: 53-74.

AMARAL, A. 1934. Collecta Herpetologica no Nordeste do Brasil. Memórias do Instituto Butantan, 8: 3-12.

AMARAL, A. 1935. Collecta Herpetologica no Nordeste do Brasil (Contribuição II). Memórias do Instituto Butantan, 9: 27-32.
AMARAL, A. 1937. Herpetological Collection from Northeastern Brazil. C. R. XII Congresso Internacional de Zoologia, 3: 1713-1719.

ARZABE, C.; SKUK, G.; SANTANA, G.G.; DELFIM, F.R.; LIMA, Y.C.C. \& ABRANTES, S.H.F. 2005. Herpetofauna da área do Curimataú, Paraíba. In F. S. Araújo; M. J. N. Rodal \& M. R. V. Barbosa. (orgs.). Pp. 264 - 280. Análise das variações da biodiversidade do Bioma Caatinga: suporte a estratégias regionais de conservação. Ministério do Meio Ambiente, Brasília, DF.

ÁVILA-PIRES, T.C.S. \& VITT, L.J. 1998. A new species of Neusticurus (Reptilia: Gymnophthalmidae) from the Rio Juruá, Acre, Brazil. Herpetologica, 54(2): 235-245.

BANDEIRA, J.M.G. 2000. Aspectos Zoogeográficos e Ecológicos da Saurofauna da Estação Ecológica de Xingó, AL/SE. Monografia (Graduação em Ciências Biológicas) (Não Publ.), Universidade Federal de Alagoas, Centro de Ciências Biológicas, Maceió, 35p.

BARBOSA, M.R.V.; LIMA, I.B.; CUNHA, J.P.; QUIRINO, Z. G.M. \& LIMA, J.R. 2003. Levantamento florístico e fitossociológico em remanescentes de Caatinga no Cariri paraibano. In: Workshop - Caatinga: Estrutura e Funcionamento. I Seminário de Avaliação (Resumos). Pp. 3.

BERTOLOTTO, C.E.V.; PELLEGRINO, K.C.M.; RODRIGUES, M.T. \& YONENAGA-YASSUDA, Y. 2002. Comparative cytogenetics and supernumerary chromosomes in the Brazilian lizard genus Enyalius (Squamata, Polychrotidae). Hereditas, 136: 51-57.

BORGES-NOJOSA, D.M. \& CARAMASCHI, U. 2003. Composição e Análise Comparativa da Diversidade e das Afinidades Biogeográficas dos Lagartos e Anfisbenídeos (Squamata) dos Brejos Nordestinos. In: I. R. Leal, M. Tabarelli \& J. M. C. Silva (eds.). Pp. 463-512. Ecologia e Conservação da Caatinga. Recife: Ed. Universitária-UFPE.

BORGES-NOJOSA, D.M. \& CASCON, P. 2005. Herpetofauna da área Reserva da Serra das Almas, Ceará. In: F. S. Araújo; M.J.N. Rodal \& M.R.V. Barbosa. (orgs.). Análise das variações da biodiversidade do Bioma Caatinga: suporte a estratégias regionais de conservação. Ministério do Meio Ambiente, Brasília, DF.

BOULENGER, G.A. 1902. List of the fishes, batrachians, and reptiles collected by the later Mr. P. O. Simons in the provinces of Mendonza and Cordova, Argentina. Ann. Mag. Nat. Hist., 9(7): 336-339.

CARVALHO, C.M. 1997. Uma nova espécie de microteíideo do gênero Gymnophthalmus do Estado de Roraima, Brasil (Sauria, Gymnophthalmidae). Papéis Avulsos de Zoologia, 40(10): 163-176. 
CASTOE, T.A.; DOAN, T.M. \& PARKINSON, C.L. 2004. Data partitions and complex models in Bayesian analysis: the phylogeny of Gymnophthalmid lizards. Systematic Biology, 53(3): 448-469.

COLE, C.J.; DESSAUER, H.C. \& MARKEZICH, A.L. 1993. Missing Link Found: The Second Ancestor of Gymnophthalmus underwoodi (Squamata: Teiidae), A South American Unisexual Lizard of Hybrid Origin. American Museum Novitattes, 3055: 1-13.

COLLI, G.R.; BASTOS, R.P. \& ARAÚJO, A.F.B. 2002. The Character and Dynamics of the Cerrado Herpetofauna. In: P.S. Oliveira \& R.J. Marquis. (orgs.). Pp. 223-241. The Cerrados of Brazil: Ecology and Natural History of a Neotropical Savanna. Columbia Unipress: New York.

CUNHA, O.R.; LIMA-VERDE, J.S. \& LIMA, A.C.M. 1991. Novo gênero e espécie de lagarto do Estado do Ceará (Lacertilia: Teiidae). Boletim do Museu Paraense Emílio Goeldi, 7(2): 163-176.

DELFIM, F.R., GONÇALVES, E.M. \& SILVA, S.T. 2006. Squamata, Gymnophthalmidae, Psilophthalmus paeminosus: Ditribution extension, new state rocord. Check List 2006, 2(3): 89-92.

DIXON, J.R. 1974. Systematic review of the genus Anotosaura (Teiidae). Herpetologica, 30(1): 13-18

ESTES, R.; QUEIROZ, K. \& GAUTHIER, J. 1988. Phylogenetic relationships within Squamata. In: R. Estes \& G. Pregill, (eds.). Pp 119-281. Phyllogenetic relationships of the lizard families. Stanford, Stanford University Press.

FREIRE, E.M.X. 1996. Estudo Ecológico e Zoogeográfico sobre a fauna de lagartos (Sauria) das Dunas de Natal, Rio Grande do Norte e da Restinga de Ponta de Campina, Cabedelo, Paraíba, Brasil. Revista Brasileira de Zoologia, 13(4): 903-921.

GALLARDO, J.M. 1969. Las especies de saurios (Reptilia) de la provincia de Santa Fe, Argentina, y consideraciones sobre su ecologia y zoogeografia. Neotropica, 15(47): 73-81.

GOVERNO DO ESTADO DA PARAÍBA/SECRETARIA DA EDUCAÇÃO/UNIVERSIDADE FEDERAL DA PARAÍBA. 1985. Atlas do Estado da Paraíba. Grafset: João Pessoa, Paraíba

HOOGMOED, M.S. \& ÁVILA-PIRES, T.C.S. 1992. Studies on the species of the South American lizard genus Arthrosaura Boulenger (Reptilia: Sauria: Teiidae), with the ressurrection of two species. Zoologische Mededelingen, 66: 453-484.

INSTITUTO DO MEIO-AMBIENTE E DOS RECURSOS NATURAIS RENOVÁVEIS - IBAMA. 2005. Eletronic database accessible at: http://www.ibama.gov.br/rn/index. php. Acessado em: 23 de maio de 2005.

MACCULLOCH, R.D. \& LATHROP, A. 2001. A New Species of
Arthrosaura (Sauria: Teiidae) from the Highlands of Guyana. Caribbean Journal of Science, 37(3-4): 174-181.

MÉLO, A.C.S. \& BANDEIRA, A.G. 2004. A Qualitative and Quantitative Survey of Termites (Isoptera) in na Open Shrubby Caatinga in Northeastern Brazil. Sociobiology, 44(3): 707-716.

NÚCLEO DE METEREOLOGIA APLICADA. 1987. Atlas climatológico do Estado da Paraíba. Editora Universitária UEPB, Campina Grande.

OLIVEIRA, P.E., BARRETO, A.M.F. \& SUGUIO, K. 1999. Late Pleistocene/Holocene climatic and vegetacional history of the Brazilian Caatinga: the fossil dunes of the middle São Francisco River. Palaeogeography, palaeoclimatology, palaeoecology, 152: 319-337.

PELLEGRINO, K.C.M.; RODRIGUES, M.T. \& YONENAGAYASSUDA, Y. 1999a. Chromosomal polymorphisms due to supernumerary chromosomes and pericentric inversions in the eyelidless microteiid lizard Notobachia ablephara (Squamata, Gymnophthalmidae). Chromosome Research, 7: 247-259.

PELLEGRINO, K.C.M.; RODRIGUES, M.T. \& YONENAGAYASSUDA, Y. 1999b. Chromosomal evolution in the Brazilian lizards of genus Leposoma (Squamata, Gymnophthalmidae) from Amazon and Atlantic rain forests: banding patterns and FISH of telomeric sequences. Hereditas, 131: 5-21.

PELLEGRINO, K.C.M.; RODRIGUES, M.T.; YONENAGAYASSUDA, Y. \& SITES, JR.,J.W. 2001. A molecular perspective on the evolution of microteiid lizards (Squamata, Gymnophthalmidae), and a new classification for the family. Biological Journal of the Linnean Society, 74:315-338.

PETERS, J.A. \& DONOSO-BARROS, R. 1970. Catalogue of the Neotropical Squamata: Part II. Lizards and Amphisbaenians. Bull. U. S. Nat. Mus., 297: viii + 293.

PRESCH, W. 1983. The lizard family Teiidae: is it a monophyletic group? Zoological Journal of the Linnean Society, 77:189197.

PRESCH, W. 1988. Phylogenetics relationships of the Scincomorpha. In: R. Estes \& G. Pregill, (eds.). Pp 471-492. Phyllogenetic relationships of the lizard families. Stanford, Stanford University Press.

QUEIROZ, A. N. \& LEMA, T. 1996. Novo registro de Colobosaura mentalis AMARAL, 1933, (Sauria; Teiidae) para o nordeste do Brasil. Biociências, 4(1): 87-90.

ROCHA, C.F.D. 2000. Biogeografia de Répteis de Restingas: Distribuição, Ocorrência e Endemismos. In F. A. ESTEVES \& I. D. LACERDA. (Eds.). Pp 99-115. Ecologia de Restingas e Lagoas Costeiras. Rio de Janeiro: NUPEM/UFRJ.

RODRIGUES, M.T. 1984a. Uma nova espécie brasileira de 
Tropidurus com crista dorsal (Sáuria, Iguanidae). Papéis Avulsos de Zoologia, 35(16): 169-175.

RODRIGUES, M.T. 1984b. Notobachia ablephara: novo gênero e espécie do nordeste do Brasil (Sáuria, Teiidae). Papéis Avulsos de Zoologia, 35(28): 361-366.

RODRIGUES, M.T. 1986a. Potencial faunístico da Caatinga. In Anais do Simpósio sobre Caatingas e sua exploração racional. Brasília, EMBRAPA, DDT. Pp. 163-170.

RODRIGUES, M.T. 1986b. Uma nova espécie do gênero Phyllopezus de Cabaceiras: Paraíba: Brasil, com comentários sobre a fauna de lagartos da área (Sauria, Gekkonidae). Papéis Avulsos de Zoologia, 36(20): 237-250.

RODRIGUES, M.T. 1986c. Um novo Tropidurus com crista dorsal do Brasil, com comentários sobre suas relações, distribuição e origem (Sáuria, Iguanidae). Papéis Avulsos de Zoologia, 36(17): 171-179.

RODRIGUES, M.T. 1991a. Herpetofauna das dunas interiores do RioSãoFrancisco:Bahia:Brasil:I.Introduçãoàárea edescrição de um novo gênero de microteiídeos(Calyptommatus) com notas sobre sua ecologia, distribuição e especiação (Sauria, Teiidae). Papéis Avulsos de. Zoologia, 37(19): 285-320.

RODRIGUES, M.T. 1991b. Herpetofauna das dunas interiores do Rio São Francisco: Bahia: Brasil: II. Psilophthalmus: um novo gênero de microteiídeos sem pálpebras (Sauria, Teiidae). Papéis Avulsos de. Zoologia, 37(20): 321-327.

RODRIGUES, M.T. 1991c. Herpetofauna das dunas interiores do Rio São Francisco: Bahia: Brasil: III. Procellosaurinus: um novo gênero de microteiídeos sem pálpebras, com a redefinição do gênero Gymnophthalmus (Sauria, Teiidae). Papéis Avulsos de. Zoologia, 37(21): 329-342.

RODRIGUES, M.T. 1992. Herpetofauna das dunas interiores do Rio São Francisco: Bahia: Brasil. V. Duas novas espécies de Apostolepis (Ophidia, Colubridae). Memórias do Instituto Butantan, 54(2): 53-59.

RODRIGUES, M.T. 1993. Herpetofauna of Paleoquaternary Sand Dunes of the middle São Francisco River: Bahia: Brazil. VI. Two New Species of Phimophis (Serpentes: Colubridae) with notes on the origin of psammophilic adaptations. Papéis Avulsos de Zoologia, 38(11): 187-198.

RODRIGUES, M.T. 1995. Filogenia e História Geográfica de uma radiação de Lagartos microteiídeos (Sauria, Teiioidea, Gymnophthalmidae). Tese (Livre-docência) (Não public.). Universidade de São Paulo, 92 p.

RODRIGUES, M.T. 1996a. A new species of lizard, genus Micrablepharus (Squamata, Gymnophthalmidae) from Brazil. Herpetologica, 52: 535-541.

RODRIGUES,M.T.1996b.Lizards, snakes, andampphisbaenians from the quaternary sand dunes of the middle Rio São
Francisco, Bahia, Brazil. Journal of Herpetology, 30(4): 513-523.

RODRIGUES, M.T. 1997. A new species of Leposoma (Squamata, Gymnophthalmidae) from the Atlantic Forest of Brazil. Herpetologica, 53(3): 383-389.

RODRIGUES, M.T. 2000. A new specie of Mabuya (Squamata: Scincidae) from the semiarid Caatingas of northeastern Brazil. Papéis Avulsos de Zoologia, 41(21): 313-328.

RODRIGUES, M.T. 2003. Herpetofauna da Caatinga. In: I. R. Leal; M. Tabarelli \& J. M. C. Silva, (eds.). Pp 181236. Ecologia e Conservação da Caatinga. Recife: Ed. Universitária-UFPE.

RODRIGUES, M.T.; KASAHARA, S. \& YONENAGAYASSUDA, Y. 1988. Tropidurus psammonastes: uma nova espécie do grupo torquatus com nota sobre seu cariótipo e distribuição (Sáuria, Iguanidae). Papéis Avulsos de Zoologia, 36(26): 307-313.

RODRIGUES, M.T; ZAHER, H. \& CURCIO, F. 2001. A new species of lizard, genus Calyptommatus, from the Caatingas of the state of Piauí, Northeastern Brazil (Squamata, Gymnophthalmidae). Papéis Avulsos de Zoologia, 41(28): 529-546.

RODRIGUES, M.T.; FREIRE, E.M.X.; PELLEGRINO, K.M.C. \& SITES JR.,J.W. 2005. Phylogenetic relationships of a new genus and species of microteiid lizard from the Atlantic forest of north-eastern Brazil (Squamata, Gymnophthalmidae). Zoological Journal of the Linnean Society, 144: 543-557.

RODRIGUES, M.T.; DIXO, M.; PAVAN, D. \& VERDADE, V.K. 2002a. A new species of Leposoma (Squamata, Gymnophthalmidae) from the remnant Atlantic Forests of the State of Bahia, Brazil. Papéis Avulsos Zoological, 42(14): 335-350.

RODRIGUES, M.T.; DIXO, M. \& ACCACIO, G.M. 2002b. A large sample of Leposoma (Squamata, Gymnophtahlmidae) from the Atlantic Forests of Bahia, the status of Leposoma annectans Ruibal, 1952, and notes on conservation. Papéis Avulsos Zoological, 42(5): 103-117.

VANZOLINI, P.E. 1974. Ecological and geographical distribution of lizards in Pernambuco, Northeastern Brazil (Sauria). Papéis Avulsos de Zoologia, 28(4): 61-90.

VANZOLINI, P.E. 1976. On the lizards of Cerrado-Caatinga contact: Evolutionary and Zoogeographical implications (Sauria). Papéis Avulsos de Zoologia, 29(16): 111-119.

VANZOLINI, P.E. 1981. A quasi-historical approach to the natural history of the differentiation of reptiles in tropical geographic isolates. Papéis Avulsos de Zoologia, 34(19): 189-204.

VANZOLINI, P.E. 1991a. Two new small species of Amphisbaena from the fossil dune field of the middle Rio São Francisco, 
State of Bahia, Brasil (Reptilia, Amphisbaenia). Papéis Avulsos de Zoologia, 37(17): 259-276.

VANZOLINI, P.E. 1991b. Two further new species of Amphisbaena from the semi-arid northeast of Brazil (Reptilia, Amphisbaenia). Papéis Avulsos de Zoologia, 37(23): 347-361.

VANZOLINI, P.E. \& CARVALHO, C.M. 1991. Two sibling and sympatric species of Gymnophthalmus in Roraima, Brasil (Sauria, Teiidae). Papéis Avulsos de Zoologia, 37(12): 173226.

VANZOLINI, P.E. \& RAMOS, A.M.M. 1977. A new species of Colobodactylus, with notes on the distribution of a group of stranded microteiid lizards (Sauria, Teiidae). Papéis Avulsos de Zoologia, 31(3):19-47.

VANZOLINI, P.E. \& WILLIAMS, E.E. 1981. The Vanishing Refuge: a mechanism for ecogeographic speciation. Papéis Avulsos de Zoologia, 34(23):251-255.

VANZOLINI, P.E.; RAMOS-COSTA, A.M.M. \& VITT, L.J. 1980. Répteis das Caatingas. Academia Brasileira de Ciências, Rio de Janeiro.

VARELA-FREIRE, A.A. 2002 A Caatinga Hiperxerófila do Seridó, a sua caracterização e estratégias para sua conservação. Academia de ciências do estado de São Paulo, São Paulo.

VELlOSO, A.G.; SAMPAIO, E.V.S.B. \& PAREYN, F.G.C. 2001. Ecorregiões: propostas para o bioma Caatinga. In: Resultados do Seminário de Planejamento Ecorregional da Caatinga/Aldeia-PE. Recife, Associação Plantas do Nordeste; Instituto de Conservação Ambiental The Nature Conservancy do Brasil. Pp. 7-33.

VITT, L.J. 1982. Sexual dimorphism and reproduction in the microteiid lizard, Gymnophthalmus multiscutatus. Journal of Herpetology, 16(3): 325-329.

YONENAGA-YASSUDA, Y. \& RODRIGUES, M.T. 1999. Supernumerary chromosome variation, heteromorphic sex chromosomes and banding patterns in microteiid lizards of the genus Micrablepharus (Squamata, Gymnophthalmidae). Chromosome Research, 7: 247-259.

YONENAGA-YASSUDA, Y.; VANZOLINI, P.E.; RODRIGUES, M.T. \& CARVALHO, C.M. 1995. Chromosome banding patterns in the unisexual microteiid Gymnophthalmus underwoodi and in two related sibling species (Gymnophthalmidae, Sauria). Cytogenetic and Cell Genetics, 70: 29-34.

Submetido em 03/09/2007. Aceito em 07/01/2008. 


\section{ANEXOS}
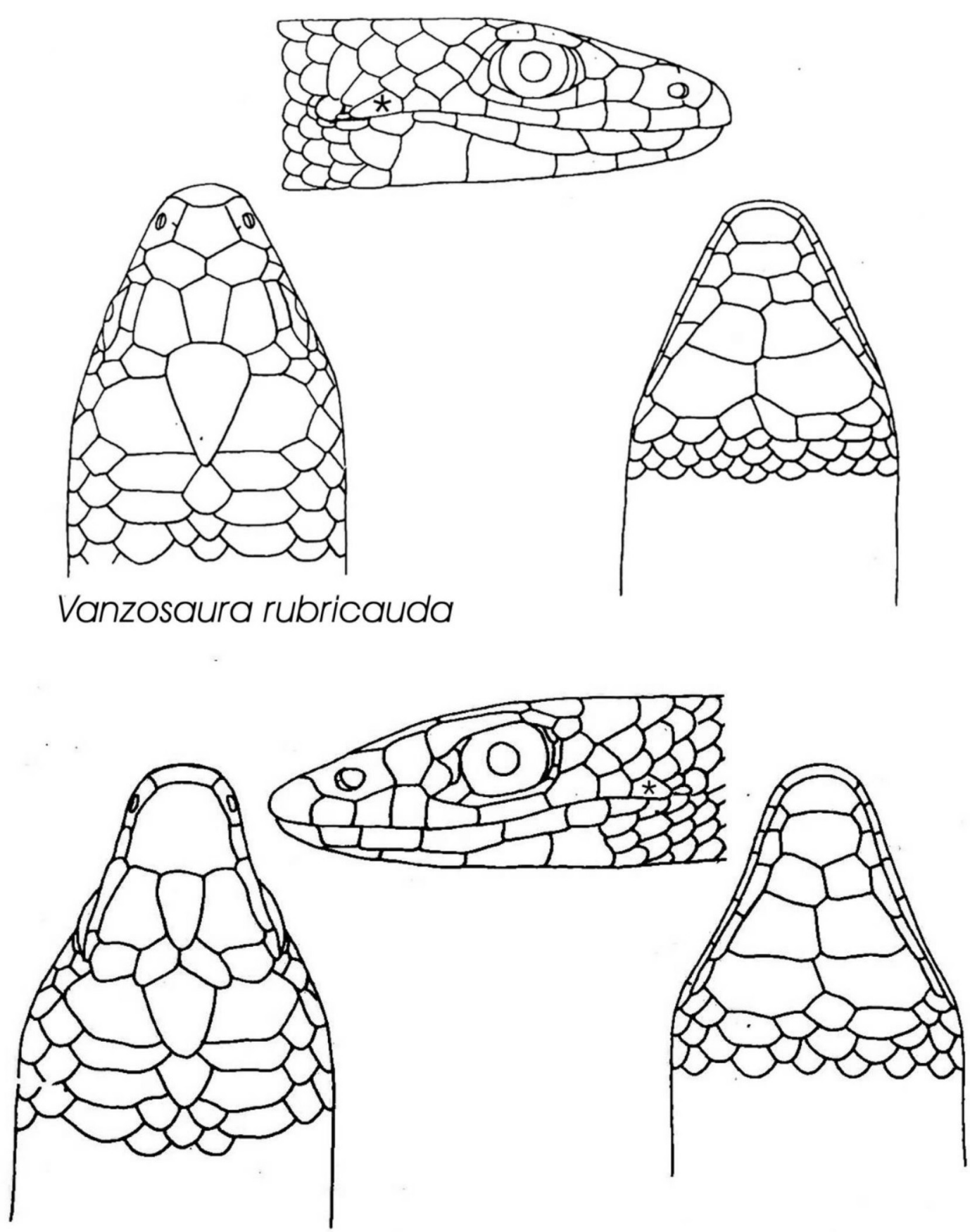

Micrablepharus maximiliani

Anexo I. Desenhos das espécies Vanzosaura rubricauda e Micrablepharus maximiliani retirados do livro "Répteis das Caatingas" (Vanzolini et al. 1980), destacando a última escama supralabial (*). Modificado de Vanzolini et al. (1980). 